\title{
Recognition of Significance of Painting from Life in Image Era
}

\author{
Yan Zhisheng ${ }^{1, \text { a }}$ \\ ${ }^{1}$ The College of Posts and Telecommunication of Wuhan Institute of Technology, Wuhan, 430070 \\ China \\ ayanzs2046@sina.com
}

Keywords: Image Era, Images, Painting from Life, Recognition .

Abstract. Image era is the current visual feature, which profoundly influences the art of painting. Images are the simulation of natural objects. Overwhelmingly depending on images might make us the distance between arts and nature larger and larger. Only by returning to the original nature to paint from life. Only in this way can artistic creation regain vigor and vitality. After entering image era, painting from life is rendered with more unprecedented new meanings. While directing painting images, the language of painting from life becomes the effective channel to strengthen live feeling of works. Painting from life can even be directly taken as the creation itself and become an independent artistic language.

\section{Creation of Painting in Image Era}

\subsection{Ossification of Creation}

At present, for most painters, the work of painting cannot be separated from photos. The majority of artists utilize photos or images to obtain materials, which replaces the previous function of sketch. Some artists even borrows the photo schema or stimulates the photo effects. Some artists even directly copy photos and images. The painting creation more and more depends on photos and images. The separation from realistic world will gradually leads to the ossification of artistic creation.

\subsection{Solution to Ossification --- Painting from Life}

At present, many painters are not willing to deepen the research on natural objects; instead, they depend more on photos or images, thus leading to the platitude and ossification caused by the pattern from documents to documents, which is far away from the fresh and capricious natural objects and life itself. The highly utilization of photos or images makes the vitality of artistic works weaker and weaker. The cost of being far away from natural objects will be definitely platitude and ossification. How to solve the ossification of painting? The key is to paint from life, which is way of painting inherited from ancient times.

\section{Painting from Life in Image Era}

\subsection{Generation and Features in Image Era}

The giant changes in modern society is the social reason giving birth to image era. Previously, text is the dominant way to acquire knowledge. Currently, image arouses huge reform in social life and thinking. Before image era, images are positioned by words. Whether it paining or scenery, they are both positioned by taking words as the criteria. Nevertheless, image does not need the hint or instruction of any word, because image itself is the way of expression. Hence, Ales Erjavec once said "I never read. I just view pictures" [1]. As the presentation, image is the nature. What the watchers could do is just to make the option between watching or not watching. As for how to watch, it is not the issue to think about, because it can must easier to watch the photographic duplication than material objects. [2]

In the aspect of media, the inundation of images makes realistic world become the think generated by media. "Stimulation is no longer the stimulation in a certain field. It is no longer the stimulation taking objects or entities for reference. It is generated in accordance with the pattern of a certain material object. The material object is like a tree without roots, which is surreal" [3]. As for that, images replace material objects and become the purely virtual definition. This kind of virtual 
definition reacts on realistic world, thus recreating the virtual definition generated by the media in the real world. "This kind of consciousness takes the real world as a set of potential photos". [4]

2.2The Rise and Falling of Images and Painting from Life

(1) The Rise of Images

The appearance of photography undermines the recording function of traditional painting in a large degree. With the development of the era, many artists realize the existing expression language of traditional paintings could not satisfy the interpretation of life experience and notions as well as the artistic expression of creativity in the new historical era. Hence, while being engaged in artistic creation, many artists' focus point and expression way is closely linked up with the popular photos or images in the current stage naturally.

The paintings of Gerhard Richter come from images. His painting works directly take photos as the materials, and make the selection among the photos collected from different sources. He said "photos are the perfectest image... The expression way and contents of photos are both my origin of thinking" [5]. As far as Gerhard Richter is concerned, photography is the most objective "second nature". Photos shall be superior to painting from life.

(2) Falling of Painting from Life

Before the rise of image era, painting from life is the basis of artistic creation. In the traditional sense of meaning, the functions of painting from life can be roughly summarized into three aspects: collecting materials, training basic skills and making direct creation. In addition, painting from life is the origin of arts, whether it is artistic form or artistic language. However, in image era, tremendous changes take place, which changes the fundamental status of painting from life in the previous artistic creation.

\section{Significance of Painting from Life}

\subsection{Connotation of Painting from Life}

In the strict sense, the connotations of painting from life come from two origins. The concept of painting from life introduced from the western world emphasizes to paint according to the natural objects, which expresses a kind of relatively objective behavioral state. As far as they are concerned, a painting shall resemble the person, object or scenery being painted...the attitude towards painting is called natural attitude by the western artists. [6] In traditional Chinese paintings, although there is no exact word to express the meaning of painting from life; however, it is always the notion to paint from life. Simply speaking, the concept of painting from life introduced from introduced from the western world is painting in nature, which requires to look at the object at each glance until the end of painting. However, the traditional Chinese concept of painting is imaginal, which describes the object in imagination and nature within the heart of people.

3.2 Painting from Life is the Origin of Arts

(1) Natural Objects Create Artistic Language

The ancient Chinese painters are always emphasizing the observation and painting from natural objects. The ancient Chinese paintings focus on creating from nature. The feature highlights the extremely regionalism in the ancient Chinese landscape paintings. The natural objects in different regions give rise to different arts. Dong Yuan and Ju Ran describe the mountains and waters in the regions southern to the Yangtze River; hence, their paintings are soft. Their technique of wrinkling renders great changes in the shapes of mountains. Nevertheless, Jing Hao and Guan Tong depict the high and distant mountains and rivers in the northern regions; hence, their style tends to be coarse and

hard, thus forming the rigid lines and technique of wrinkling.

The works of Sai Shang are taken as the watershed between classical arts and modern arts. However, his arts still have a certain corresponding relation with the reality. "A small patch of cloth is definitely impossible to match the broad landscape in the countryside; however, a painter can see the corresponding relation between the painting and the scenery from the arrangement of pigment" [7].

(2) Artistic Rules Deposited in Natural Objects 
Artistic rules come from the natural objects depicted by artists. "Painting creation can follow objective rules and laws, which exist in objective reality. The painting rules come from objective reality" [8]. Actually, the process to create artistic works is to perceive the movement of the original materials in the front by creating a certain form or structure corresponding to the material of stimulation. The mountains and the method of showing the shades and texture of rocks and mountains by light ink strokes in traditional Chinese landscape painting are corresponding to each other in the words of Shi Tao is because to make the mountains and rocks into a painting, the first step is to depict the mountains by the method, which definitely makes the mountains. In the process, different methods to make different shapes of mountains came into being.

\section{Recognition of Significance of Painting from Life in Image Era}

\subsection{Changes in Significance of Painting from Life}

In image era, most painters make the creation by second nature, which is represented by photos or images. However, some painters still insist on taking painting from life as the method of creation, such as Lucien Freud, who takes painting from life as the creation in notion; and Liu Xiaodong, who paints photos by the language of painting from life.

(1) Concept of Painting from Life

Lucien Freud insists on creation in the way of painting from life. His painting structure is relatively simple. There is no narrativity in his paintings, but the theatrical effects are created. The figures in the paintings seem to be in the extremely nervous state. However, from the expression of the eyes, there is the sense of vacillating. Under his pen, the emotions are closely related to the vigorous humanity, thus forming an organic whole. He adopts the way and language of painting from life. The final works still have extremely strong spiritual nature. As for him, painting from life is creation.

(2) Language of Painting from Life

The paintings by Liu Xiaodong do not emphasize painting from life. Instead, the depiction is also made by means of photos. The daily life depicted in the images always renders the feeling of captured from camera, from which, it can obviously seen the influence of photographed pictures on his creation. The lens sense renders extremely strong facticity to the works of Liu Xiaodong. In the meanwhile, his paintings adopt the language of painting from life, which renders thick scene feeling. Although what he paints are photos, the language of painting from life restores the originality and distinctiveness of his works, and extend the freshness and truth of life itself into the construction of ideas.

\subsection{Painting from Life is Creation}

Arts are derived from objective world or reflects realistic life. In this way, watching is the premise of picture. Watching is not only the visual physics or physiological activity, but also involved with the role played by consciousness, thus giving rise to different channels and consequences. In this way, the watching as the starting point of painting from life develops according to specific time and site. The value lies in whether the new space is explored.

Just from the works of Liu Xiaodong, painting from life can be directly taken as the creation itself. Lucien Freud utilizes the way and language of painting from life, to penetrate painting from life itself into the behavior of creation. In his works, there is extremely strong spiritual feeling. The works of Liu Xiaodong uses the true feeling of photos. In the meanwhile, he also adopts extremely proficient, simple and natural language of painting from life. The language of painting from life renders his works the scene feeling of being personally on the scene.

\section{Conclusion}

The current world is a world penetrated with images. The ubiquitous images are unscrupulously undermining paintings. In turn, it can also render new resources and stimulants to paintings. To create by making effective use of images can grasp the spiritual core of the era, reflect the features of the era 
and largely promote artistic creation. However, the existing image world is easy to be decayed and rigidified by artistic creation, thus making artistic creation far from the source of image world --- the real world. The real world is actually rich, colorful and inexhaustible. To recognize painting from life has specially importance significance on the artistic creation in the image era.

\section{References}

[1] [Slovenia] Ales Erjavec. Image Era [M]. Interpreted by Hu Julan and Zhang Yunpeng. Changchun: Jilin People's Publishing House, 2003, pl.

[2] [Germany] Walter Benjamin. Artistic Words in the Era of Technical Replication [M]. Interpreted by Hu Shi. Hangzhou: Zhejiang Literature and Art Publishing House, 2005, p65.

[3] [America] Mary Warner and Maria [M]. Interpreted by Hao Hongwei and Ni Yang. Proofread by Ma Chuanqi. Jinan: Shandong Pictorial Publishing House, 2005, p47.

[4] [America] Susan Sontag. On Photography [M]. Interpreted by Ai Honghua and Mao Jianxiong. Changsha: Hunan Arts Publishing House, 1999, p17.

[5] Zhu Qi, Fuzziness of Image---Richter's Artistic Notes and Interviews [M]. Changsha: Hunan Arts Publishing House, 2007, p15.

[6] Ye Qing, Depicting Objects Vividly---Research on Realistic Tradition in Chines Paintings [M]. Nanchang: Jiangxi People's Publishing House, 2005, p5.

[7] [Britain] Brian Maggie. Stories of Philosophy [M]. Interpreted by Ji Guibao. Beijing: Life, Reading and New Knowledge Sanlian Bookstore, 2002, p203.

[8] Yang Chengyin. Study on Shitao's Paintings [M]. Xi'an: Sha'anxi Normal University Press, 2004, p7. 